\title{
Disparities between Development Regions and District Development Committees in Nepal
}

\author{
Julien Vandernoot • Camille Van Hove
}

Published online: 10 July 2014

(C) International Atlantic Economic Society 2014

\section{JEL E62}

Nepal is in a transitional process nowadays. The country is about to be reorganized in different sub-national levels of government. According to our calculations, important disparities exist both among development regions and among district development committees (DDC) in terms of contribution to the government revenue and expenditures.

At this moment, Nepal is officially divided into five development regions, 14 administrative zones and 75 districts development committees (DDC) themselves subdivided into local governments, which are the municipalities and the village development committees (GURUNG H., Nepal: Atlas and statistics, 2006). This research note aims to define what the intrinsic ability of the development regions and the DDC's to generate revenue is. Could they have sufficient resources to support their own expenditures thanks to the revenue that they can generate?

In order to answer these questions, data were extracted from the consolidated financial statements of the fiscal year 2011-2012, published by the government of Nepal. This report gives the amount of money earned and spent by the Nepalese government that can be attributed to each territory. The central development region generates $79.49 \%$ of the government revenue and $59.26 \%$ of the expenditures are dedicated to this area. At the DDC's level, Kathmandu and Parsa are the sources of $54.60 \%$ of the total government revenue. Kathmandu is the target of $42.29 \%$ of the government expenditures. Even if Parsa is an important source of revenue, the government spends only $0.99 \%$ of its money for it. Consequently, it is clear that some implicit transfers exist between the districts in Nepal.

To draw some comparisons, both total revenue and expenditures were divided by the population census for June 2011 (central Bureau of Statistics, National population and housing census, 2012).

Firstly, at the Development region level, the central region has a more important contribution per capita to the government revenue. As a matter of fact, the revenue 
generated by this territory during the fiscal year 2011-2012 reached 20,329.73 NRP (Nepal's average equals $9322.18 \mathrm{NRP}$ ), while the contribution of the other regions were lower than 5,000 NRP per capita. For instance, the amount generated by the central region was almost 20 times greater than the one produced by the far-west region. The weighted standard deviation equals 8,405.54 NRP. Secondly, with regards to the government expenditures, the positions of different regions change. The level of expenditures dedicated to the central region stays higher than the other ones, but even if government revenue (per capita) from far-west region was evaluated at 1,025.32 NRP, the expenditures per capita reached 7,997.57 NRP for the fiscal year 2011-2012. The expenditures weighted standard deviation is less important than the revenue-side one and equals 5,754.55 NRP. It could also be interesting to compare government revenue to expenditures per capita for each development region, in order to see if some are financing others, and if so, which ones. All the development regions have lower per capita revenue than what they cost, except the central region (758.11 NRP). It can be explained by the fact that all the expenditures are taken into account while only the revenue (tax and others) is computed for the revenue-side. Concerning the fiscal year 2011-2012, the greatest difference between revenue and expenditures exists in the midwest region (-7,903.82 NRP).

At the district level, the ones which generate highest revenue per capita are located in the central region: Kathmandu, Parsa and Lalitpur. Kathmandu requires a high level of expenditures per capita, which leads to a negative difference between revenue and expenditures (-35 758.59 NRP). However, some districts are pools of revenue for the government: five of them in the central region, one in the eastern part of the country and one in the western region. Indeed, these areas can generate higher government revenue than required. Finally, assuming a constant population growth rate, government revenue and expenditures per capita have been set to 100 to allow time comparisons while neutralizing the effect of inflation. On both the revenue and expenditures sides, the main trends remain for the development regions between 2009-2010 and 2011-2012. Some changes are noticeable on the district level. For example, the largest decrease in per capita revenue in absolute terms has been measured in Kathmandu (from 606 to 446) and the largest increase in Lalitpur (from 786 to 930).

To conclude, disparities between Nepalese development regions and DDC's are not negligible. These are quite stable at times, at least for the periods studied here. The decentralization process of Nepal has to be take into account because some districts and development regions are generating lower revenue for the government while they need high expenditures to provide public services and goods. 